\title{
Efficacy of percutaneous short segment fixation on the treatment of Magerl A3 thoracolumbar fractures: a retrospective study
}

hongheng lin ( $\sim$ peter.lin2013@foxmail.com )

Third Affiliated Hospital of Guangzhou University of Chinese Medicine https://orcid.org/0000-00027887-407X

\section{Xiaoting Ou}

Third Affiliated Hospital of Guangzhou University of Chinese Medicine

Wenchao Li

Third Affiliated Hospital of Guangzhou University of Chinese Medicine

\section{Minyuan Chen}

Third Affiliated Hospital of Guangzhou University of Chinese Medicine

\section{Caijun Liu}

Third Affiliated Hospital of Guangzhou University of Chinese Medicine

\section{Ling Mo}

Third Affiliated Hospital of Guangzhou University of Chinese Medicine

\section{Chao Yuan}

Third Affiliated Hospital of Guangzhou University of Chinese Medicine

Hui Zhu

Third Affiliated Hospital of Guangzhou University of Chinese Medicine

\section{De Liang}

First Affiliated Hospital of Guangzhou University of Chinese Medicine

\section{Research article}

Keywords: Intermediate screw, Percutaneous short segment fixation, Thoracolumbar fracture, Bone mineral density

Posted Date: June 8th, 2020

DOI: https://doi.org/10.21203/rs.3.rs-31598/v1

License: (c) (1) This work is licensed under a Creative Commons Attribution 4.0 International License. Read Full License 


\section{Abstract}

\section{Background}

This is a retrospective study to evaluate the efficacy of percutaneous short segment fixation (PSSF) with or without intermediate screws in Magerl A3 thoracolumbar $(T L)$ fractures accompanied with low bone mineral density (BMD).

\section{Methods}

From January 2017 to December 2018, 30 patients diagnosed with Magerl A3 TL fractures having a BMD between $0.5 / \mathrm{cm} 2$ and $1 \mathrm{~g} / \mathrm{cm} 2$ in the lumbar vertebrae with intact neurological functions and a history of major trauma who underwent PSSF with or without intermediate screws were enrolled in this study. The patients were divided into two groups of those with intermediate screws (group F) or without (group S). The operation time and intra-operation blood loss were recorded. Oswestry disability index (ODI) questionnaire and visual analogue scale (VAS) were employed as clinical assessments and quantified. Radiographic follow-up assessed according to the Cobb angle (CA), Vertebral wedge angle (VWA), and anterior vertebral body height (AVBH).

Results

Loose screws were observed in 4 of the 30 enrolled patients. Significant differences were observed in operation time and intra-operative blood loss between the two groups. The enrolled patients' clinical results (VAS and ODI scores) were good, however, no significant differences during all follow-up periods were present between the two groups. Radiographic evaluation (CA, VWA and AVBH) improved immediately after surgery, but significant correction loss was observed in the follow-up periods, especially in the first month. Radiographic evaluation demonstrated no significant differences between the two groups.

\section{Conclusion}

Although the patients' clinical results were satisfactory, PSSF could not resist the correction loss in Magerl A3 TL fractures accompanied with BMD below 1 $/ \mathrm{cm} 2$. Accordingly, the use of intermediate pedicle screws may be unnecessary due to their limited ability in resisting correction loss and increasing operation time as well as intra-operation blood loss.

\section{Background}

The thoracolumbar (TL) region (T11-L3) is the most common area of spinal fractures due to its biomechanical characteristics; TL fractures account for $60-70 \%$ of spinal fractures $(1,2)$. As the population ages, an increasing number of TL fractures accompanied with low bone mineral density (BMD) will occur, however, its treatment is controversial (3). Conservative therapy with extended periods of bed rest leads to bone loss, while open long segment pedicle screw fixation causes intra-operative 
trauma to the para-spinal muscle, extensive blood loss and significant postoperative pain with loss of motion segments $(4,5)$. Percutaneous vertebroplasty (PVP), percutaneous kyphosis vertebroplasty (PKP) and bone cement augmented pedicle screw fixation are used to treat severely osteoporotic spinal fractures, but cement leakage related complications are of concern $(6,7)$.

Percutaneous short segment fixation (PSSF) is a minimally invasive short segment pedicle screw fixation involving just one segment above and below the level of the fracture, which has been growing in popularity thanks to its numerous advantages such as preservation of posterior musculature, segment motion and good clinical results $(8,9)$. The addition of intermediate screws at the level of the fracture may significantly improve the stability of short-segment pedicle screw fixation and reduce the ratio of fixation failure, but most clinical trials were performed in patients with normal bone mineral density (1012). To our knowledge, few in vitro studies sought to determine the efficacy of PSSF in treating TL fractures accompanied with low BMD.

The purpose of this retrospective study was to evaluate the efficacy of PSSF with or without intermediate screws in the treatment of Magerl (13) A3 TL fractures with a BMD of under $1 \mathrm{~g} / \mathrm{cm}^{2}$.

\section{Methods}

Patient population

Medical records of patients with spinal fractures who underwent PSSF in our department from January 2017 to December 2018 were retrospectively reviewed. Of the 196 admitted patients with spinal fractures, 47 were diagnosed with isolated Magerl A3 TL fractures with a BMD between $0.5 / \mathrm{cm}^{2}$ and $1 \mathrm{~g} / \mathrm{cm}^{2}$ in the lumbar region, intact neurological functions and a history of major trauma who underwent PSSF with or without intermediate screws. Of these 47 patients, 17 were excluded from this study due to incomplete clinical data, which included less than one year of follow up, poor medical compliance or low quality of radiographic images. Accordingly, 30 patients (12 male and 18 female) with an average age of $64.97 \pm 7.61$ years and a BMD of $0.73 \pm 0.12 \mathrm{~g} / \mathrm{cm}^{2}$ were enrolled in this study.

\section{Operative methods}

Following general anesthesia, patients were placed in a hyperextended prone position on a radiolucent operating table to promote the reduction of the fracture. A paramedian $2 \mathrm{~cm}$ incision overlying the target spinal segment was made and extended into the underlying subcutaneous tissue. The entry point of the screw was chosen at the three-point (left side) or nine-point (right side) of the pedicle edge of the anteroposterior (AP) image using a track awl. The surgeon drilled holes along the center axis of the pedicles under fluoroscopic guidance to ensure that the track awl would not pass the medial edge of the pedicle in the AP image until it passed though the posterior edge of the vertebra in the lateral image. After checking the medial and caudal angulation, a guide wire was inserted into the hole, and the track awl was removed. Percutaneous dual-threaded pedicle screw (sanyou, China) was inserted along the guide wire into the vertebra under fluoroscopic guidance. Bilateral pedicle screws were inserted into the pedicles 
above and below the fracture. Whether bilateral intermediate screws were used depended on the experience of surgeon. After the screws were put in place, rods with appropriate length were contoured according to the normal physiological sagittal alignment of the fracture level prior to insertion. Kyphosis was collected by cantilever reduction of the rods in the screws.

\section{Postoperative management}

Patients were encouraged to stand with braces within three days following the operation, and postoperative standing plain images were obtained. All patients were asked to return to our department for clinical and radiographic assessment after one month, three months, and one year postoperatively. The implant was routinely removed one to two years following surgery to avoid screw breakages and to obtain additional segment movement.

\section{Data collection}

The age, gender, weight, height, BMD, load sharing classification (LSC), intra-operative blood loss, operative time, and level of fracture were recorded. All patients took upright radiographs three days, one month and one-year post-operation, and their clinical outcomes were quantified using the visual analogy scale (VAS) and Oswestry disability index (ODI) questionnaires. The radiographic observation index consisted of sagittal Cobb angle (CA), vertebral wedge angle (VWA) and anterior vertebral body height $(A V B H)$. The CA refers to the angle between the superior endplate of the upper vertebra and inferior endplate of the lower vertebra. The VWA was the angle between the superior and inferior endplates of the fracture vertebrae. AVBH refers to the percentage of the mean value for the adjacent vertebra (14). All data were reviewed by an independent observer who had no involvement in the treatment.

Statistical analyses

SPSS (ver.22; SPSS, Inc., USA) was utilized for all statistical analyses. The data were presented as mean \pm standard deviation, and comparisons of the continuous data between Group $S$ and Group $F$ such as age, BMD, LSC, weight, height, operation time, intra-operative blood loss, VAS, ODI, CA, VWA, and AVBH were analyzed using the independent sample t test. Unordered data (gender, injury mechanism, and complication) and ordered data (fracture level) were analyzed using the Fisher test and rank sum test. Comparisons of CA at different times in each group were performed using one-way-repeated-measuresdesign Analysis of Variance. A P-value $<0.05$ was considered to be statistically significant.

\section{Results}

Groups $\mathrm{S}$ and $\mathrm{F}$ included 19 and 11 patients, respectively. Their baseline demographics, BMD, LSC, fracture site and cause of injury of the patients in both groups are shown in Table 1, where no significant differences were observed between the two groups. The injured vertebral segments were T11 in 1 patient, T12 in 3 patients, L1 in 15 patients, L2 in 9 patients and L3 in 2 patients. Injuries were incurred after falling from a height in 24 patients, car accident in 3 patients and crash in 3 patients. 
Operation time and intra-operative blood loss

The operation time in groups $S$ and $F$ was $82.00 \pm 9.80$ and $121.55 \pm 14.14 \mathrm{~min}$, and the intra-operative blood loss was $22.63 \pm 6.53$ and $32.73 \pm 4.67 \mathrm{ml}$, respectively. Significant differences were present in operation time and intra-operative blood loss between the two groups $(P<0.05)($ Table 1$)$.

\section{Clinical outcomes}

Pre-operatively, the VAS scores were determined to be $8.32 \pm 1.11$ and $8.45 \pm 0.69$ in groups $S$ and $F$, respectively, which significantly decreased in both groups during the post-operative period $(P<0.05)$. However, no significant differences in the VAS score were observed at the follow-up periods between the two groups $(P>0.05)$ (Table 2).

At three days, one month and one year following surgery, the ODI scores in both groups were significantly improved compared to those before surgery $(P<0.05)$, however, no significant differences were observed between the two groups, demonstrating a similar change in VAS scores (Table 2).

Radiological outcomes

Significant improvement from the baseline in the CA, VWA and AVBH of the fractured vertebrae after surgery were observed in both groups $(P<0.05)$, though correction loss of the CA, VWA and AVBH were also observed during the follow up $(P<0.05)$. In group $F$, the $C A$, VWA and AVBH had no significant differences compared to group $S$ prior to the operation as well as three days, one month and one year after surgery $(P>0.05)$. During the follow-up periods of the one month and one year post-operative datasets, the correction loss of CA, VWA, and AVBH of the fractured vertebrae demonstrated no significant differences between the two groups (Table 3).

Surgery-related complications

Loose screws were observed in five patients (four in group S, one in group F), and all were treated conservatively and showed favorable outcomes in their final follow-up. Nonunion, neurological impairment, and infection were not evident during the follow-up periods in both groups (Figs. 1 and 2).

\section{Discussion}

Treatment for TL fractures without neurological deficit has been controversial for decades $(15,16)$. Currently, conservative therapy for Magerl A0, A1, and A2 TL fractures and surgical therapy for Magerl B and $C$ is generally accepted, however, no general consensus exists for Magerl A3 and A4 fractures without neurological deficits $(16,17)$. LSC is widely used in the clinic setting and numerous authors have suggested that short segment fixation (SSF) should be performed for TL fractures with an LSC between 4 and 6, the grade for most cases of Magerl A3 fractures, while long segment fixation should be done for those having an LSC above $7(18,19)$. With the development of minimally invasive surgical techniques, percutaneous pedicle screws have been widely used in the treatment of spinal fractures as it confers 
many advantages compared to open surgery such as reduced blood loss and decreased muscular injury, leading to minor postoperative pain and shorter recovery times (8). As the purpose of surgery is to correct the deformity and stabilize the fracture level rather than decompressing it, PSSF may be adopted in Magerl A3 fractures without neurological impairment. Various studies have put forward that adding intermediate screws at the level of the fracture could reduce correction loss during follow-up while increasing intra-operation time and blood loss $(10,12)$. To our knowledge, clinical in vitro studies pertaining to SSF were almost carried out in young patients or in patients with normal BMD. For severe osteoporotic vertebral fractures, percutaneous vertebroplasty (PVP), percutaneous kyphosis vertebroplasty (PKP) and bone cement augmented pedicle screw fixation are commonly used in the elderly with satisfactory clinic outcomes, though the complications like cement leakage and adjacent vertebral fractures are of concern (20). Due to the aging population, an increasing number of middle-aged patients suffer from TL fractures with osteopenia, for which treatment is ambiguous. Conservative therapy with extended periods of bed rest leads to bone loss, nonunion, kyphosis and back pain (21). PVP and PKP is not an appropriate mode of treatment as they are not old enough, and many expect to return to normal levels of activity. Bone cement augmented screw fixation may serve as an option, however, complications like cement leakage is concerning. Furthermore, due to cultural factors, patients in China believe that metallic implants kept in their bodies is not conducive to good health in the long-term.

In fact, few in vitro studies evaluated the efficacy of PSSF in treating TL fractures accompanied with low BMD. In this study, low BMD was defined to be below $1 \mathrm{~g} / \mathrm{cm}^{2}$ as previous studies demonstrated that the pullout force of the pedicle was highly influenced by BMD, especially when BMD was lower than $1 \mathrm{~g} / \mathrm{cm}^{2}(22,23)$. Specifically, in patients with low BMD, the pullout force of the pedicle screw decreased compared to those with normal BMD. However, the demand for pullout force also decreased due to a less active lifestyle in the elderly. With the development of screw fixations such as dual-threaded pedicle screws, which may have a stronger pullout force than their single-threaded counterparts (24), and minimally-invasive surgical technology that protects the back muscle better than open surgery (11), we hypothesized that patients with low BMD who underwent PSSF may attain stabilization following surgery. In this study, patients with BMD in their lumbar region between $1 \mathrm{~g} / \mathrm{cm}^{2}$ and $0.5 \mathrm{~g} / \mathrm{cm}^{2}$ and a definite history of major trauma, which was distinguished from osteoporosis with pathological fractures, were enrolled. Operation time (average of $121.55 \mathrm{~min}$ ) was longer, and blood loss (average of $32.73 \mathrm{ml}$ ) was found to be increased in type $\mathrm{F}$ compared to those (average of $82.00 \mathrm{~min}$ and $22.63 \mathrm{ml}$ ) in type $\mathrm{S}$, signifying that increasing the number of intermediate screws may also increase intra-operation trauma. The clinical and functional outcomes (VAS and ODI) were observed to be satisfactory in both groups without significant differences during all follow-up periods.

The radiographic outcomes (CA, VWA, $A V B H)$ in both groups improved immediately following surgery, however, all suffered significant correction loss during follow-up periods, with most instances occurring in the first month (Tables 2, 3). Evidently, patients in type F gained more correction in deformity and suffered additional correction loss during follow-up periods (Tables 2,3), though no significant differences were observed between the two groups, which may have been due to the study's small sample size. The final 
results of both groups in the one-year follow-up had no significant differences. Some authors suggested that PSSF with intermediate screws may effectively better restore vertebral height intra-operatively and maintain deformity correction after surgery in patients with normal BMD (11). In our study, however, intermediate screws did not constitute the same function as in patients with low BMD. Screw fixation is closely related to BMD. Koichiro suggested that in BMD below $0.67 \mathrm{~g} / \mathrm{cm}^{2}$, performing pedicle screw fixation for posterior lumbar inter-body fusion confers a higher risk of nonunion (25). Experimental studies have demonstrated that a pull-out force of a $7.0 \mathrm{~mm}$ pedicle screw was $1054 \mathrm{~N}$ in vertebrae with normal BMD, which decreased to $269.5 \mathrm{~N}$ when BMD was $0.5 \mathrm{~g} / \mathrm{cm}^{2}$ (Jikei grading III) (22). Here, patients in both groups immediately gained deformity collection after surgery, while the VAS and ODI taken after three days was found to be significantly improved compared to that of prior to surgery. Accordingly, patients gained better stabilization compared to before surgery. This stabilization is very limited and could not maintain the deformity correction needed in daily life, gradually leading to correction loss in the follow-up periods. In patients with normal BMD, the correction loss was much lower. Guven reported that the correction loss of CA in those with TL fractures who underwent PSSF with or without intermediate screws averaged 2.8 and 3.7, respectively (10), far less than that of our study (average of 9.36 and 5.47, respectively). Although the correction loss in the follow-up was significant, patients in both groups gained improvements in function. To this effect, radiographical outcomes did not align with their functional outcomes. As clinical results were satisfactory in both groups, though they poorly maintained the deformity correction, it is suggested that the purpose of PSSF in TL A3 fractures is to stabilize the fracture level and prevent exacerbation of the deformity rather than correct the deformity. If deformity correction and maintenance is necessary, long segment fixation or bone cement augmented screw fixation may serve as a better choice. In the present study, PSSF with intermediate screws led to longer operation times and additional intra-operation blood loss, and no significant differences were observed in correction loss or clinical outcome index between both groups, suggesting that intermediate screws may be unnecessary for the patients involved in this study.

All pedicle screws were inserted under fluoroscopic guidance, and no neurological impairment was detected in both groups. Loose screws were observed in five patients (four in group S, one in group F) without significant differences between the two groups. The reason for screws being loose remains unclear, however, it may have been due to the low pull-out force of pedicle screws in those with low BMD. In our hypothesis, the incidence of instrument failures such as screw breakage and loose screws may be lower in group $F$, reaching this conclusion proved difficult due to the small number of patients enrolled in this study.

The primary limitation in our study is that it was conducted on a small population. Hence, detecting statistical differences between the two groups and analyzing the correlation between correction loss and BMD was difficult. In addition, it is hard to predict long-term outcomes of the study as the follow-up period was just one year. Future large-scale studies with longer follow-up periods are required for further elucidation. 


\section{Conclusions}

Though clinical outcomes were satisfactory, PSSF could not resist the correction loss in Magerl A3 TL fractures accompanied with a BMD below $1 \mathrm{~g} / \mathrm{cm} 2$. Furthermore, intermediate pedicle screws may be unnecessary due to their limited ability in resisting correction loss while increasing operation time and intra-operative blood loss

\section{Abbreviations}

PSSF: percutaneous short segment fixation

TL: thoracolumbar

BMD: bone mineral density

ODI: Oswestry disability index

VAS: visual analogue scale

CA: Cobb angle

VWA: Vertebral wedge angle

AVBH: anterior vertebral body height

PVP: percutaneous vertebroplasty

PKP: percutaneous kyphosis vertebroplasty

AP: anteroposterior

LSC: load sharing classification

\section{Declarations}

Ethics approval and consent to participate

This study was approved by the Ethics Committee of The Third Affiliated Hospital of Guangzhou University of Chinese Medicine.

Consent for publication

Not applicable

Availability of data and materials 
Not applicable

Competing interests

The authors declare that they have no competing interests

Funding

No

Authors' contributions

$\mathrm{HL}$ analyzed and interpreted the data in our study and was a major contributor in writing the manuscript.

WL conceived and designed the study. XO and MC completed the data collection of radiographic observation index. $\mathrm{CJ}$ and LM completed the data collection of clinical observation index. $\mathrm{CY}$ and $\mathrm{HZ}$ was responsible for the software analysis of the data. DL reviewed and edited the article. All authors read and approved the final manuscript.

Acknowledgements

Not applicable

\section{Reference}

1. Joaquim AF, de Almeida Bastos DC, Jorge Torres HH, Patel AA. Thoracolumbar Injury Classification and Injury Severity Score System: A Literature Review of Its Safety. Global Spine J. 2016;6(1):80-5.

2. Leucht P, Fischer K, Muhr G, Mueller EJ. Epidemiology of traumatic spine fractures. Injury. 2009;40(2):166-72.

3. Rajasekaran S, Kanna R, Schnake K, Vaccaro A, Schroeder G, Sadiqi S, et al. Osteoporotic Thoracolumbar Fractures-How Are They Different?-Classification and Treatment Algorithm. Journal of Orthopaedic Trauma. 2017;31:S49-S56.

4. Grossbach AJ, Dahdaleh NS, Abel TJ, Woods GD, Dlouhy BJ, Hitchon PW. Flexion-distraction injuries of the thoracolumbar spine: open fusion versus percutaneous pedicle screw fixation. Neurosurg Focus. 2013;35(2):E2.

5. Court C, Vincent C. Percutaneous fixation of thoracolumbar fractures: current concepts. Orthop Traumatol Surg Res. 2012;98(8):900-9.

6. Zhan Y, Jiang J, Liao H, Tan H, Yang K. Risk Factors for Cement Leakage After Vertebroplasty or Kyphoplasty: A Meta-Analysis of Published Evidence. World Neurosurg. 2017;101:633-42.

7. Janssen I, Ryang YM, Gempt J, Bette S, Gerhardt J, Kirschke JS, et al. Risk of cement leakage and pulmonary embolism by bone cement-augmented pedicle screw fixation of the thoracolumbar spine. Spine J. 2017;17(6):837-44. 
8. Fu Z, Zhang X, Shi Y, Dong Q. Comparison of Surgical Outcomes Between Short-Segment Open and Percutaneous Pedicle Screw Fixation Techniques for Thoracolumbar Fractures. Med Sci Monit [Internet]. 2016 2016/09//; 22:[3177-85 pp.]. Available from: http://europepmc.org/abstract/MED/27602557, https://doi.org/10.12659/msm.896882 https://europepmc.org/articles/PMC5024561, https://europepmc.org/articles/PMC5024561? pdf=render.

9. Schmidt R, Cakir B, Mattes T, Wegener M, Puhl W, Richter M. Cement leakage during vertebroplasty: An underestimated problem? European spine journal : official publication of the European Spine Society, the European Spinal Deformity Society, and the European Section of the Cervical Spine Research Society. 2005;14:466-73.

10. Guven O, Kocaoglu B, Bezer M, Aydin N, Nalbantoglu U. The Use of Screw at the Fracture Level in the Treatment of Thoracolumbar Burst Fractures. Journal of spinal disorders \& techniques. 2009;22:41721.

11. Li K, Li Z, Ren X, Xu H, Zhang W, Luo D, et al. Effect of the percutaneous pedicle screw fixation at the fractured vertebra on the treatment of thoracolumbar fractures. Int Orthop. 2016;40.

12. Mahar A, Kim C, Wedemeyer M, Mitsunaga L, Odell T, Johnson B, et al. Short-Segment Fixation of Lumbar Burst Fractures Using Pedicle Fixation at the Level of the Fracture. Spine (Phila Pa 1976). 2007;32:1503-7.

13. Magerl F, Aebi M, Gertzbein SD, Harms J, Nazarian S. A comprehensive classification of thoracic and lumbar injuries. Eur Spine J. 1994;3(4):184-201.

14. Mumford J, Weinstein JN, Spratt KF, Goel VK. Thoracolumbar burst fractures. The clinical efficacy and outcome of nonoperative management. Spine (Phila Pa 1976). 1993;18(8):955-70.

15. Rosenthal BD, Boody BS, Jenkins TJ, Hsu WK, Patel AA, Savage JW. Thoracolumbar Burst Fractures. Clin Spine Surg. 2018;31(4):143-51.

16. Abudou $M$, Chen $X$, Kong $X$, Wu T. Surgical versus non-surgical treatment for thoracolumbar burst fractures without neurological deficit. 62013.

17. Rometsch E, Spruit M, Härtl R, McGuire R, Gallo-Kopf B, Kalampoki V, et al. Does Operative or Nonoperative Treatment Achieve Better Results in A3 and A4 Spinal Fractures Without Neurological Deficit?: Systematic Literature Review With Meta-Analysis. Global Spine Journal. 2017;7:350-72.

18. Gelb D, Ludwig S, Karp JE, Chung EH, Werner C, Kim T, et al. Successful treatment of thoracolumbar fractures with short-segment pedicle instrumentation. J Spinal Disord Tech. 2010;23(5):293-301.

19. Rojas-Tomba F, Hernández-Ruiz Á, Menéndez-Quintanilla I, Quevedo-Puerta D, Moriel-Durán J, Villanueva-Pareja F. Radiologic and Functional Outcomes in Unstable Thoracolumbar Fractures Treated With Short-segment Pedicle Instrumentation. Clinical spine surgery. 2016;30.

20. Zhang Y-Z, Kong L-D, Cao J-M, Ding W-Y, Shin DA. Incidence of subsequent vertebral body fractures after vertebroplasty. Journal of clinical neuroscience : official journal of the Neurosurgical Society of Australasia. 2014;21. 
21. Rajasekaran S. Thoracolumbar burst fractures without neurological deficit: The role for conservative treatment. European spine journal : official publication of the European Spine Society, the European Spinal Deformity Society, and the European Section of the Cervical Spine Research Society. 2009;19 Suppl 1:S40-7.

22. Soshi S, Shiba R, Kondo H, Murota K. An Experimental Study on Transpedicular Screw Fixation in Relation to Osteoporosis of the Lumbar Spine. Spine (Phila Pa 1976). 1991;16:1335-41.

23. Halvorson T, Kelley L, Thomas K, Whitecloud T, Cook S. Effects of Bone Mineral Density on Pedicle Screw Fixation. Spine (Phila Pa 1976). 1994;19:2415-20.

24. Brasiliense LB, Lazaro BC, Reyes PM, Newcomb AG, Turner JL, Crandall DG, et al. Characteristics of immediate and fatigue strength of a dual-threaded pedicle screw in cadaveric spines. Spine J. 2013;13(8):947-56.

25. Okuyama K, Abe E, Suzuki T, Tamura Y, Chiba M, Sato K. Influence of bone mineral density on pedicle screw fixation: a study of pedicle screw fixation augmenting posterior lumbar interbody fusion in elderly patients. Spine J. 2001;1(6):402-7.

\section{Tables}

Table 1 Baseline demographics of the patient cohort 


\begin{tabular}{|c|c|c|c|}
\hline Parameter & Group S & Group F & $\mathrm{P}$ value \\
\hline Number of patients & 19 & 11 & \\
\hline Age, year & $64.63 \pm 5.36$ & $65.55 \pm 10.76$ & 0.76 \\
\hline Gender, males/females & $5 / 14$ & $7 / 4$ & 0.06 \\
\hline $\mathrm{BMD}, \mathrm{g} / \mathrm{cm} 2$ & $0.74 \pm 0.12$ & $0.72 \pm 0.13$ & 0.60 \\
\hline LSC & $5.16 \pm 0.69$ & $5.55 \pm 0.69$ & 0.15 \\
\hline Fracture level & & & 0.53 \\
\hline $\mathrm{T} 11$ & 1 & 0 & \\
\hline $\mathrm{T} 12$ & 3 & 0 & \\
\hline L1 & 8 & 7 & \\
\hline $\mathrm{L} 2$ & 6 & 3 & \\
\hline L3 & 1 & 1 & \\
\hline Mechanism of fracture & & & 0.18 \\
\hline Fall from height & 17 & 7 & \\
\hline Car accident & 1 & 2 & \\
\hline Crash & 1 & 2 & \\
\hline Operation time (min) & $82.00 \pm 9.80$ & $121.55 \pm 14.14$ & 0.00 \\
\hline Intra-operative blood loss (ml) & $22.63 \pm 6.53$ & $32.73 \pm 4.67$ & 0.00 \\
\hline
\end{tabular}

Table 2 The change of VAS, ODI, CA, VWA and AVBH in the pre- and post-operative period 


\begin{tabular}{|c|c|c|c|}
\hline Variable & Group S & Group F & $\mathrm{P}$ value \\
\hline \multicolumn{4}{|l|}{ VAS } \\
\hline Prep & $8.32 \pm 1.11$ & $8.45 \pm 0.69$ & 0.71 \\
\hline$p$ & $3.16 \pm 0.69$ & $2.91 \pm 0.54$ & 0.31 \\
\hline $1 \mathrm{~m}$ postop & $1.53 \pm 0.70$ & $1.18 \pm 0.60$ & 0.18 \\
\hline 1 y postop & $0.21 \pm 0.42$ & $0.09 \pm 0.30$ & 0.41 \\
\hline \multicolumn{4}{|l|}{ ODI } \\
\hline Prep & $86.68 \pm 8.98$ & $89.00 \pm 6.62$ & 0.46 \\
\hline $3 \mathrm{~d}$ postop & $26.63 \pm 6.66$ & $23.73 \pm 5.24$ & 0.22 \\
\hline $1 \mathrm{~m}$ postop & $11.53 \pm 6.10$ & $9.18 \pm 5.60$ & 0.31 \\
\hline 1 y postop & $4.79 \pm 1.75$ & $4.73 \pm 1.19$ & 0.92 \\
\hline \multicolumn{4}{|l|}{$\mathrm{CA}\left({ }^{\circ}\right)$} \\
\hline Prep & $14.58 \pm 12.57$ & $15.36 \pm 7.74$ & 0.85 \\
\hline $3 \mathrm{~d}$ postop & $4.58 \pm 11.78$ & $1.18 \pm 9.32$ & 0.42 \\
\hline $1 \mathrm{~m}$ postop & $9.47 \pm 11.59$ & $8.18 \pm 12.84$ & 0.78 \\
\hline 1 y postop & $10.05 \pm 12.04$ & $10.55 \pm 12.72$ & 0.92 \\
\hline \multicolumn{4}{|l|}{ VWA $\left(^{\circ}\right)$} \\
\hline Prep & $17.58 \pm 4.30$ & $18.73 \pm 6.53$ & 0.57 \\
\hline $3 \mathrm{~d}$ postop & $7.63 \pm 3.17$ & $5.45 \pm 3.05$ & 0.08 \\
\hline $1 \mathrm{~m}$ postop & $10.74 \pm 4.470$ & $11.82 \pm 6.113$ & 0.58 \\
\hline 1 y postop & $11.16 \pm 4.65$ & $12.00 \pm 6.56$ & 0.68 \\
\hline
\end{tabular}

AVBH (\%)

Prep $\quad 64.67 \pm 13.53 \quad 56.96 \pm 10.32 \quad 0.11$

3 d postop $\quad 89.82 \pm 4.87 \quad 91.67 \pm 6.23 \quad 0.37$ 


\begin{tabular}{llll}
\hline Variable & Group S & Group F & P value \\
\hline 1 m postop & $81.12 \pm 10.03$ & $77.66 \pm 13.32$ & 0.43 \\
1 y postop & $80.18 \pm 9.78$ & $76.05 \pm 12.58$ & 0.32 \\
\hline
\end{tabular}

Table 3 The correction loss of CA, VWA, AVBH

\begin{tabular}{|c|c|c|c|c|c|c|}
\hline \multirow[t]{2}{*}{ Group } & \multicolumn{3}{|c|}{$1 \mathrm{~m}$ postop } & \multicolumn{3}{|c|}{1 y postop } \\
\hline & $\mathrm{CA}\left({ }^{\circ}\right)$ & $\operatorname{VWA}\left({ }^{\circ}\right)$ & AVBH (\%) & $\mathrm{CA}\left({ }^{\circ}\right)$ & $\operatorname{VWA}\left({ }^{\circ}\right)$ & AVBH (\%) \\
\hline S & $5.16 \pm 4.56$ & $3.63 \pm 4.45$ & $10.44 \pm 9.69$ & $5.84 \pm 4.59$ & $4.21 \pm 4.81$ & $10.87 \pm 9.97$ \\
\hline $\mathrm{F}$ & $5.82 \pm 5.10$ & $5.45 \pm 5.68$ & $11.01 \pm 11.71$ & $5.91 \pm 5.50$ & $5.36 \pm 5.61$ & $13.48 \pm 11.48$ \\
\hline $\mathrm{P}$ value & 0.72 & 0.34 & 0.89 & 0.97 & 0.56 & 0.52 \\
\hline
\end{tabular}

Figures 

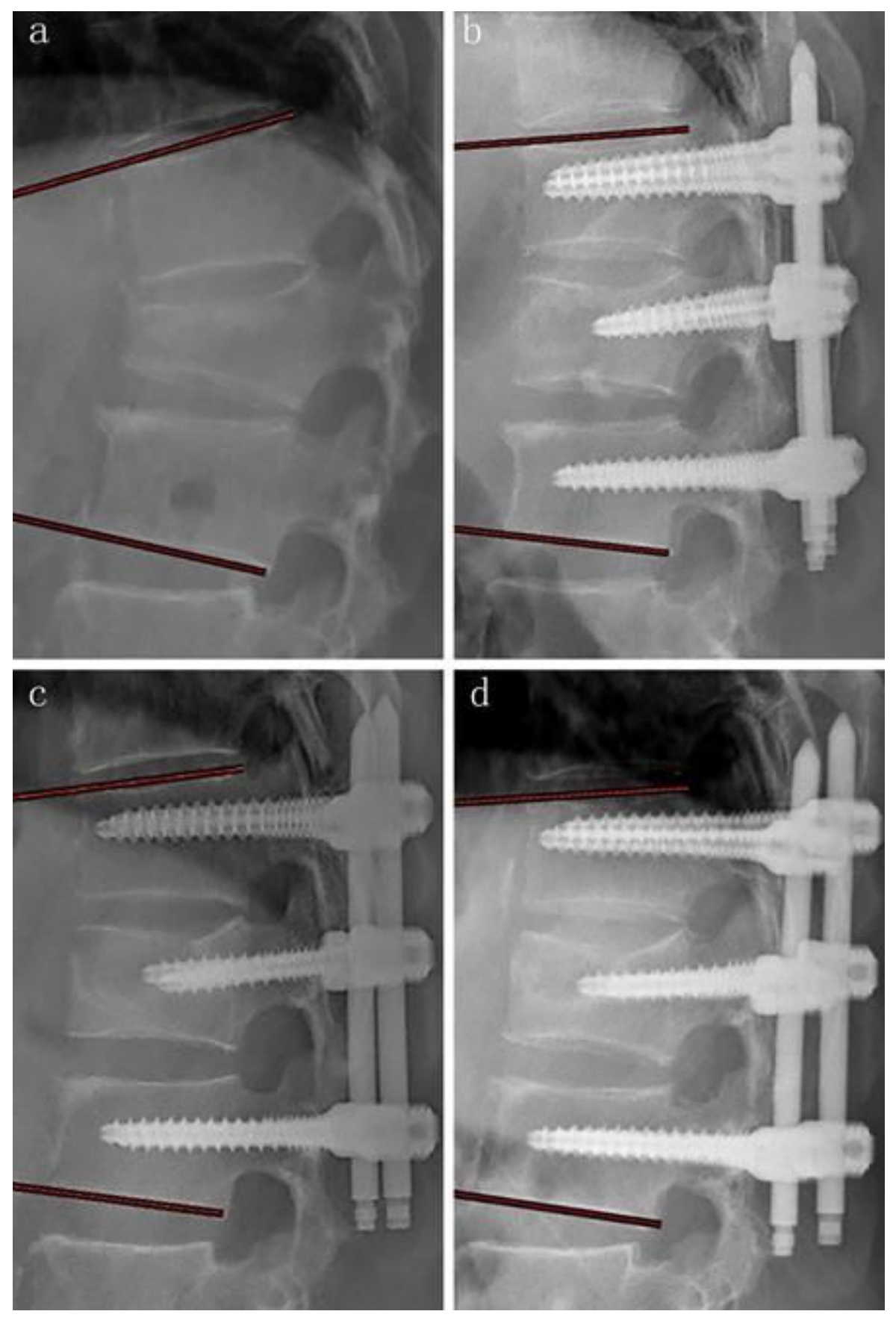

\section{Figure 1}

Preoperative and post-operative films of a 65-year-old man with L1 compressive fracture caused by crashed. (a) Preoperative film showing a kyphotic deformity and loss of anterior vertebral body height. (b) Lateral film in the $3 \mathrm{~d}$ after surgery showing the significant improvement of anterior vertebral body height and kyphotic deformity. (c),(d) lateral films in 1 month and 1 year after surgery indicating the CA increasing from $10^{\circ}$ in $3 \mathrm{~d}$ post-operative to $14^{\circ}$ in 1 month post-operative and no significant correction loss of $\mathrm{CA}$ in follow up later. 


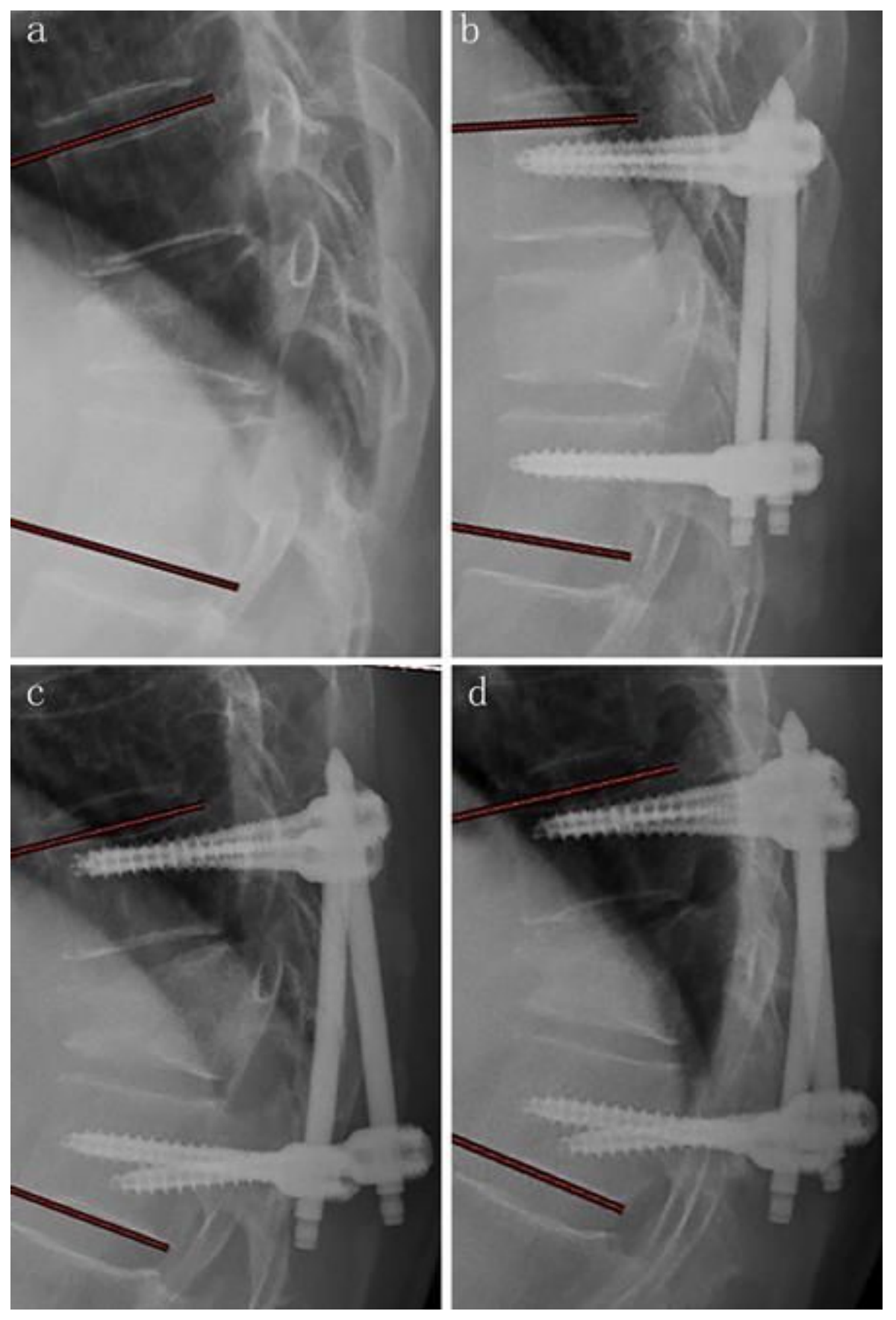

\section{Figure 2}

Preoperative and postoperative films of a 66-year-old man with T11 compressive fracture caused by fall from height. (a) Preoperative film showing a kyphotic deformity and loss of anterior vertebral body height. (b) Lateral film in $3 \mathrm{~d}$ after surgery showing the significant improvement of anterior vertebral body height and kyphotic deformity. (c) ,(d) Lateral film in $1 \mathrm{~m}$ after surgery showing screw loose in one of screws in T12 with significant correction loss and no significant correction loss of CA in follow up later. 